\title{
Maksiller yan keser dişteki aksesuar kök nedeniyle oluşan periodontal cebin tedavisi: Olgu sunumu
}

\author{
Mehmet Sağlam ${ }^{1}$, Serhat Köseoğlu ${ }^{1}$, İsmail Taşdemir ${ }^{1}$, Fahrettin Kalabalık
}

Selcuk Dent J, 2016; 3: 34-38

Basvuru Tarihi: 12 Temmuz 2015 Yayına Kabul Tarihi: 01 Mart 2016

\author{
öz \\ Maksiller yan keser dişteki aksesuar kök nedeniyle \\ oluşan periodontal cebin tedavisi: Olgu sunumu
}

Servikal mine uzantıları, mine incileri ve palatal yivler gibi diş ile ilişkili faktörler periodontal hastalık oluşumuna neden olabilirler. Aksesuar kök oluşumu nadir görülen anomalilerdendir. $\mathrm{Bu}$ rapor kronik periodontitisli 63 yaşındaki erkek hastanın vaka sunumudur. Maksiller sol yan keser dişin kökünün mesio-palatinal yüzeyinde $7 \mathrm{~mm}$ cep derinliği ile birlikte aksesuar kök benzeri yapı tanımlanmıştır. $\mathrm{Bu}$ aksesuar kök benzeri yapı faz I periodontal tedavi ve endodontik tedavi sonrası cerrahi olarak eksize edilmiştir. Cerrahi sonrası periodontal iyileşme sorunsuzdu ve periodontal cep derinliği cerrahiden 3 ay sonra $7 \mathrm{~mm}$ 'den 4mm'ye düșmüştür. Bu dental anomalilerin erken tespiti, periodontitisin etkin tedavisinde büyük klinik öneme sahiptir.

\section{ANAHTAR KELIMELER}

Diş mobilitesi, periodontal cep, risk faktörleri

\section{ABSTRACT}

Treatment of periodontal pocket caused by accessory root in maxillary lateral teeth: Case report

Tooth-related factors, such as cervical enamel projections, enamel pearls and palatal grooves are contributing factors to periodontal disease. Accessory root formation anomalies are rarely seen. This report is a case presentation of a 63-year-old male with chronic periodontitis. An accessory root-like structure with a $7 \mathrm{~mm}$ probing depth on the mesio-palatinal surface of the root of maxillar left lateral incisor was identified. The accessory root-like structure was surgically excised after phase I periodontal therapy and endodontic treatment. Periodontal healing was uneventful and periodontal pocket reduced from $7 \mathrm{~mm}$ to $4 \mathrm{~mm} 3$ months after surgery. Early recognition of these dental abnormalities has a great clinical significance in effectively treating periodontitis.

\section{KEYWORDS}

Periodontal pocket, risk factors, tooth mobility

görülmesine rağmen, üst çene yan keser dişlerdeki aksesuar kök oluşumu nadir görülen anomalilerdendir (Yavuz ve ark. 2008, Du ve ark. 2013). Aksesuar kökün, kök gelişimi esnasında travmadan kaynaklı veya esas olarak genetik nedenlerden dolayı oluşabileceği belirtilmiştir.

Bu vaka raporunda endodontik ve periodontal lezyon bulunan aksesuar köke sahip üst çene yan keser dişin başarılı tedavisi sunulmuştur.

\section{OLGU}

63 yaşında hipertansiyonu olan erkek hasta dişeti kanaması ve 22 nolu dişindeki mobilite şikayeti sebebiyle İzmir Kâtip Çelebi Üniversitesi Diş Hekimliği Fakültesi'ne başvurmuştur. Hastanın Ağız, Diş ve Çene Radyolojisi Kliniğindeki muayenesinden sonra Periodontoloji Kliniğine sevki yapılmıştır. Alınan anamnez sonucunda hastanın hipertansiyon hastası olduğu öğrenilmiştir. Yapılan klinik muayenede ağız

\footnotetext{
1 İzmir Kâtip Çelebi Üniversitesi Diş Hekimliği Fakültesi Periodontoloji Anabilim Dalı, İzmir

2 İzmir Kâtip Çelebi Üniversitesi Diş Hekimliği Fakültesi Ağız, Diş ve Çene Radyolojisi Anabilim Dalı, İzmir
} 
hijyeninin yetersiz olduğu, sondlamada dişetinde kanama, 11, 12, 13, 16, 17, 21, 22, 23, 26, 27, 31, 32, $35,36,43,46,47$ ve 48 nolu dişlerinde periodontal cepler tespit edilmiştir. Hastanın asıl şikâyeti olan 22 nolu dişte Miller sınıf 2 mobilite ve mezialde $7 \mathrm{~mm}$ periodontal cep tespit edilmiş olup, radyografide periodontal cebin olduğu bölgede aksesuar bir kök varlığı ve aynı zamanda perapikal bölgede bir lezyon dikkati çekmiştir (Resim 1). Hastaya diştaşı temizliği ve oral hijyen motivasyonu yapıldıktan sonra, 22 nolu dişine tek seansta endodontik tedavi yapıldı. Bu tedavilerden 1 hafta sonra hastaya kök yüzeyi düzleştirmesi işlemi yapıldı ve aynı hafta içinde cerrahi randevusu verildi. Cerrahi operasyondan önce, hastanın 22 nolu dişi 21 ve 23 nolu dişlere geçici olarak splintlendi. Bu işlem cerrahi esnasında ve sonrasında artabilecek mobiliteyi engellemek ve yara iyileşmesi için stabil bir ortam oluşturmak maksadı ile yapıldı. Cerrahi operasyon günü hastaya ilgili bölgenin labialine ve palatinaline lokal infiltrasyon anestezisi (Ultracain D-S Forte, Aventis, Türkiye) yapıldı. Aksesuar kök ve cep bölgesine ulaşmak için hem labialden hemde palatinalden tam kalınlık mukoperiosteal flep kaldırıldı (Resim 2). İlgili bölgedeki granülasyon dokuları temizlendikten sonra aksesuar kök eksize edildi (Resim 2). Eksize edilen bölge frezler yardımı ile düzeltildikten sonra kökte herhangi bir perforasyonun olmadığı gözlendi. Böylece ek bir kök dolgusuna ihtiyaç duyulmadı. Aksesuar kökün büyüklüğü $6 \mathrm{~mm}$ kadardı (Resim 2). İlgili bölgedeki kök yüzeyi periodontal küretler (Hu-Friedy, Chicago, IL, ABD) yardımı ile düzleştirildikten sonra flep orijinal konumuna getirildikten sonra 4-0 ipek sütür ile dikildi (Resim 2). Hastaya operasyon sonrası enfeksiyon kontrolü için 7 gün boyunca günde iki kez amoksisilin klavulanik asit (Augmentin-BID® $625 \mathrm{mg}$ ) ve $\% 0.15$ benzidamin hidroklorür ve $\% 0.12$ klorheksidin glukonat içerikli gargara (Kloroben, Drogsan, Ankara), ağrı kontrolü için ilk gün 2 defa, daha sonra ağrı oldukça kullanılmak üzere flurbiprofen tablet (Majezik Film Tablet 100mg, Sanovel, İstanbul) reçete edildi. Operasyon sonrası 10. günde dikişler alındı. Operasyondan 3 ay sonra yapılan klinik muayenede 22 nolu dişin mesialindeki cebin $4 \mathrm{~mm}$ 'ye düştüğü, mobilitenin ise fizyolojik mobilite sınırlarında olduğu gözlendi. Dişeti rengi ve kıvamı da normal kabul edilebilir sınırlarda olup, sondlamada kanama yoktu (Resim 3). Dişteki diastema ise hem estetik açıdan hemde gıda kaçışını engellemek maksadı ile restoratif olarak kapatıldı (Resim 3).

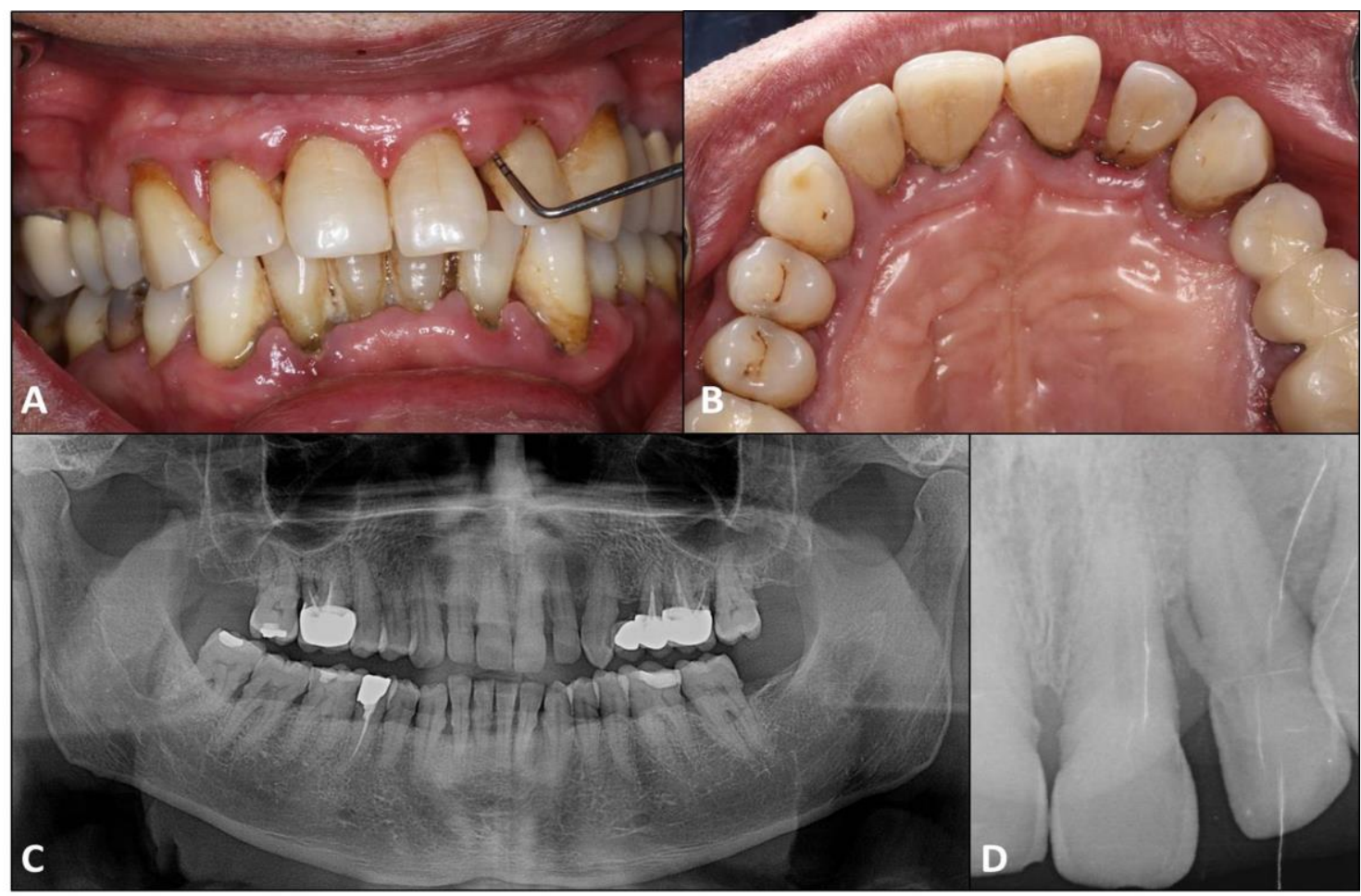

Resim 1.

Başlangıç klinik ve radyografik görünüm

a ) Klinik vestübüler görünüm

b ) Klinik palatinal görünüm

c ) Ortopanaromik film görüntüsü

d ) 22 nolu dişin perapikal film görüntüsü 


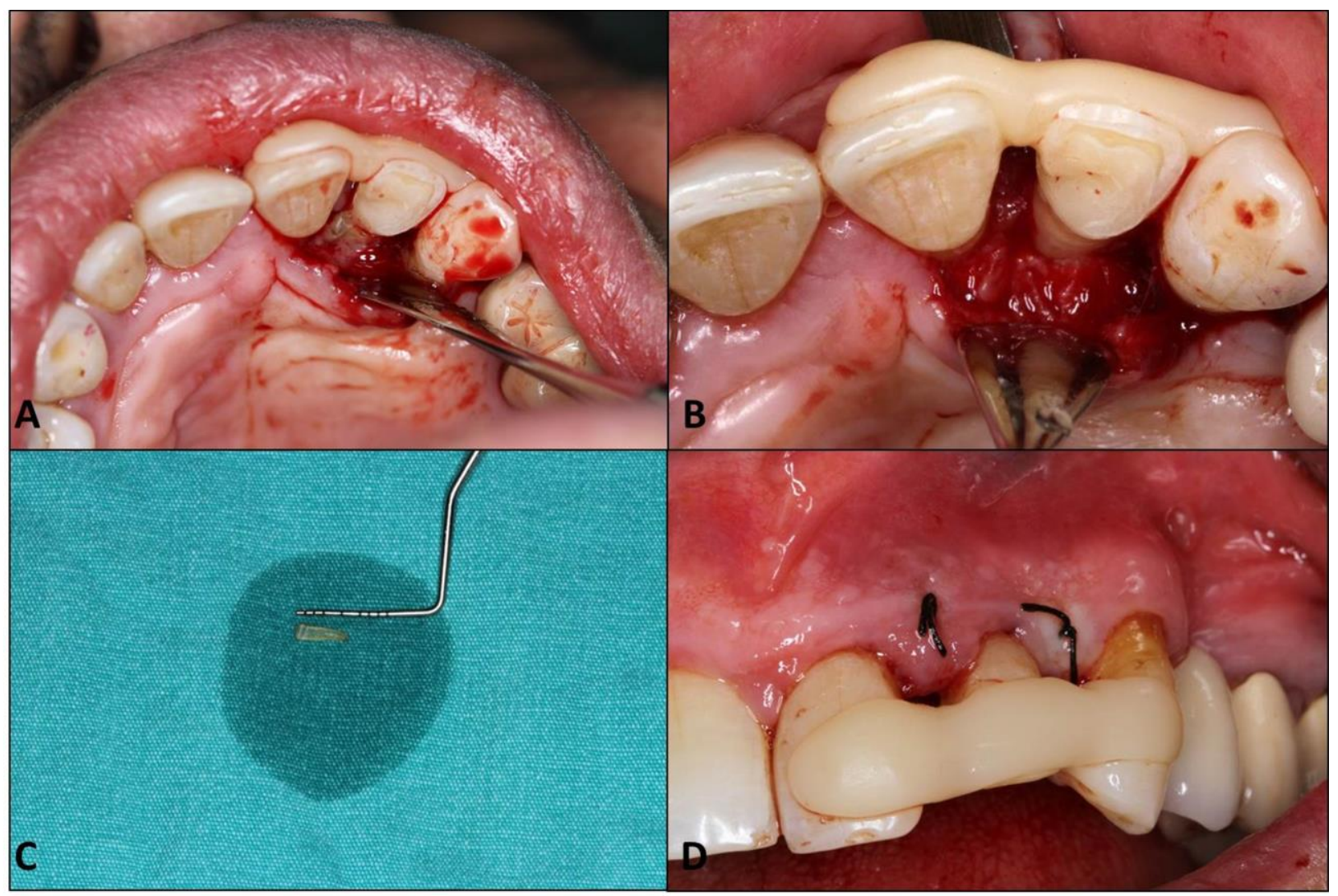

Resim 2.

Operasyon görünümü

a ) Palatinal flep kaldırıldıktan sonra aksesuar kökün görünümü

b ) Aksesuar kök eksize edildikten sonra klinik görünüm

c ) Eksize edilen aksesuar kökün klinik görünümü

d ) 4-0 ipek sütür ile kapatılan tam kalınlık flebin klinik görünümü

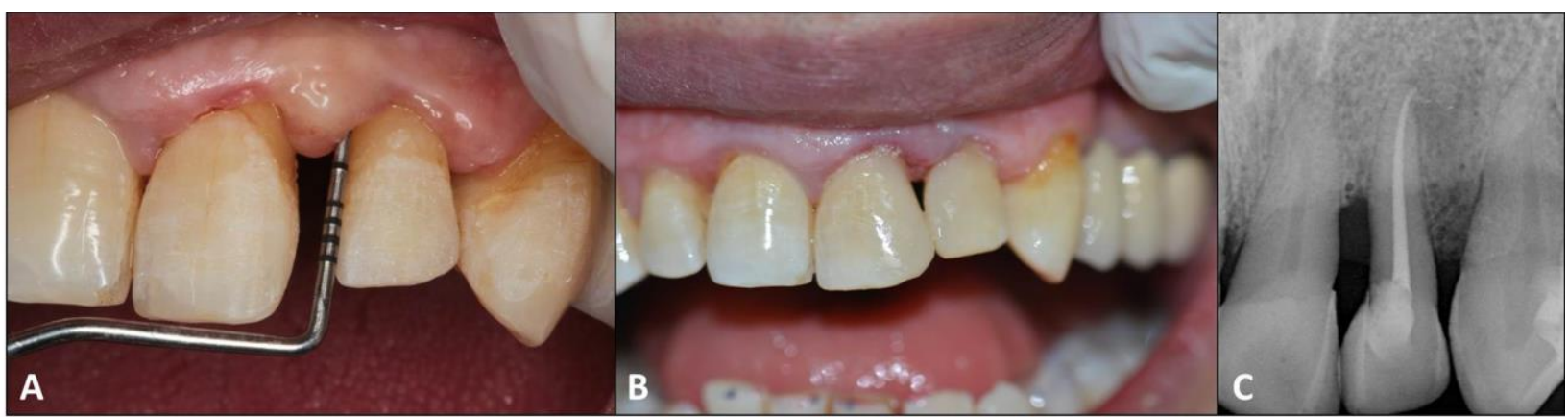

Resim 3.

a ) Cerrahi operasyondan 3 ay sonrası klinik görünüm

b ) 21 ve 22 nolu dişlerin arasındaki diastema kapatıldıktan sonraki klinik görünüm

c ) Cerrahi operasyon sonrası 22 nolu dişin radyografik görünümü 


\section{TARTIŞMA}

Mine incileri, servikal mine uzantıları ve köklerdeki yiv ve oluklar sıklıkla lokalize periodontal yıkım ile ilişkili olup, yardımcı etiyolojik faktör olarak düşünülmektedir (Matthews ve Tabesh 2004, Yavuz ve ark. 2008, Du ve ark. 2013). Aksesuar kökler alt çene köpek, küçük ve büyük azı dişlerinde daha sık görülmesine rağmen, üst ve alt çene keser dişlerde nadir görülmektedir (Yavuz ve ark. 2008, Du ve ark. 2013, Kocsis ve Marcsik 1989). Bu durumun etiyolojisi tam olarak bilinememesine rağmen kök oluşumu esnasında Hertwing epitelyal kök kınının belirli bir travmaya maruz kalması sonucu oluşabileceği öne sürülmüştür (Kocsis ve Marcsik 1989). Bununla beraber aksesuar kök oluşumunun kök oluşumu esnasında odontoblastların fonksiyonlarındaki değişikliğe bağıı oluşabileceği de belirtilmiştir (Du ve ark. 2013).

Kogon ve ark. alt santral keser dişte aksesuar bir kök rapor etmişler, mine-sement birleşiminin $1 \mathrm{~mm}$ altında aksesuar kök içerisinde aksesuar kök kanalını gözlemişlerdir (Kogon 1984). Kocsis ve Marcsik rapor ettikleri aksesuar kök oluşumunun içinde kök kanalı gözlemleyememişlerdir (Kocsis ve Marcsik 1989). Yavuz ve ark. üst çene yan keser dişin $7 \mathrm{~mm}$ periodontal cep derinliğine sahip distal kısımda aksesuar kök tespit etmişlerdir. İlgili dişe kök kanal tedavisi yapıldıktan sonra cerrahi operasyonla aksesuar kökü rezeke edip, ilgili bölgedeki kemik defektini otojen kemik grefti ile doldurmuşlardır. Bir yıl sonraki kontrolde ilgili bölgedeki cep derinliğinin 3-4 $\mathrm{mm}$ olduğu, radyografide ise lezyonun tamamen iyileştiğini rapor etmişlerdir (Yavuz ve ark. 2008). Du ve ark. şiddetli mobilite gösteren üst santral keser dişin $7 \mathrm{~mm}$ periodontal cep derinliğine sahip mesial kısımda aksesuar kök tespit etmişlerdir. Faz I tedaviye rağmen dişteki mobilitenin azalmaması sonucu dişi çekmişlerdir. Klinik ve histolojik incelemelerde çekilen dişin kökü üzerindeki aksesuar kökün keskin kenarlı, $7 \mathrm{~mm}$ boyutlarında ve kök kanalı içermediğini rapor etmişlerdir (Du ve ark 2013).

$\mathrm{Bu}$ vaka raporunda üst yan keser dişin mesialindeki aksesuar kökün bulunduğu yerde $7 \mathrm{~mm}$ periodontal cep ve dişte Miller sınıf 2 mobilite mevcuttu. Çıkarılan aksesuar kök yaklaşık $6 \mathrm{~mm}$ uzunluğunda olup kök kanalı içermiyordu. İlgili dişin periodontal ve endodontik tedavisi sonucu başarılı klinik ve radyografik iyileşme gözlenmiştir. Lokalize şiddetli periodontal yıkım görülen dişlerde aksesuar kök oluşumları gibi anatomik anomaliler yapılacak klinik ve radyografik muayenelerde gözden kaçırıımamalı ve oluşan yıkımın daha da ilerlememesi için acilen gerekli prosedürler başlatılmalıdır. 


\title{
KAYNAKLAR
}

Armitage GC, 1999. Development of a classification system for periodontal diseases and conditions. Ann Periodontol, 4, 1-6.

Du J, Wang $X$, Zhang J, Yan S, Wang L, and Yang $P$, 2013. The Possible Effect of an Accessory Root-Like Structure on Periodontitis: A Clinical and Histologic Case Report. Clin Adv Periodontics, 3, 33-38.

Evcil M, Özcan E, Köseoğlu M, 2009. Anormal kök formasyonlu üst santral kesicinin endodontik tedavisi-bir vaka raporu. Atatürk Ünv Diş Hek Fak Derg, 19, 203.

Flemmig TF, 1999. Periodontitis. Ann Periodontol, 4, 3238.

Gher ME, Vernino AR, 1980. Root morphology--clinical significance in pathogenesis and treatment of periodontal disease. J Am Dent Assoc, 101, 627-633.

Kocsis GS, Marcsik A, 1989. Accessory root formation on a lower medial incisor. Oral Surg Oral Med Oral Pathol, 68, 644-645.

Kogon S. Unusual malformed root, 1984. Oral Surg Oral Med Oral Pathol, 57, 580.

Listgarten MA, 1988. The role of dental plaque in gingivitis and periodontitis. J Clin Periodontol, 15, 485487.

Matthews DC, Tabesh M, 2004. Detection of localized tooth-related factors that predispose to periodontal infections. Periodontol 2000, 34, 136-150.

Olsson M, Lindhe J, 1991. Periodontal characteristics in individuals with varying form of the upper central incisors. J Clin Periodontol, 18, 78-82.

Yavuz MS, Keles A, Ozgoz M, Ahmetoglu F, 2008. Comprehensive treatment of the infected maxillary lateral incisor with an accessory root. J Endod, 34, 1134-1137.

\section{Yazışma Adresi:}

\author{
Arş.Gör.Dt.İsmail TAŞDEMIR \\ İzmir Katip Çelebi Üniversitesi \\ Diş Hekimliği Fakültesi \\ Periodontoloji Anabilim Dalı, İzmir \\ Tel : + $902323254040-2600$ \\ Faks : +90 2323252535 \\ E-mail: ismailtsdmr@gmail.com
}

